\title{
Schiff's base derivatives of murrayanine demonstrated enhanced anti-oxidant activity than its parent moiety
}

\author{
Ruchi S. Shivhare ${ }^{1,2, *}$, Debarshi Kar Mahapatra ${ }^{1 *}$, Rajani R. Nair ${ }^{2}$, Swati N. Deshmukh² \\ 1'Department of Pharmaceutical Chemistry, Kamla Nehru College of Pharmacy, Nagpur 441108, Maharashtra, INDIA. \\ ${ }^{2}$ Department of Pharmaceutical Chemistry, Alard College of Pharmacy, Pune 410027, Maharashtra, INDIA.
}

\begin{abstract}
Objective: Free radicals like superoxide anion radical $\left(\mathrm{O}_{2}{ }^{-}\right)$, hydroxyl radical (HO.), alkyl radical (R.), alkoxy radical (RO.), peroxy radical (ROO.) and nitric oxide radical (NO.) often leads to oncogenic proliferation, damage deoxyribosyl backbone of DNA, accelerate oxidation of polydesaturated fatty acids, amino acids, and several other co-factors. Several carbazole moieties present in M. koenigii L. like murrayanine, mahanimbine, curryanine, kurryam have been reported to exhibit good anti-oxidant activity. The present research represents an effort to develop few novel hybridized derivatives of murrayanine (an active carbazole derivative) by reacting with various small ligands like urea, semi carbazide and thio semi carbazide with an intention to develop Schiff's base compounds with higher and potent anti-oxidant activity than its parent moiety (murrayanine). Methods: The study protocol involved DPPH radical scavenging assay and determining in vitro reducing activity of the semi-synthetic derivatives. Results: The study revealed that compound 5 exhibited highest anti-oxidant activity $\left(\mathrm{IC}_{50}\right.$ of $\left.6.5 \mu \mathrm{M}\right)$, followed by derivative 3 which displayed activity at $\mathrm{IC}_{50}$ value of $7.3 \mu \mathrm{M}$, which was superior as compared to murrayanine 1 which scavenge the radical at $I C_{50}$ of $7.6 \mu \mathrm{M}$. However, two semi-synthetic compounds ( 2 and 4 ) exhibited lesser activity compared to murrayanine, $\mathrm{IC}_{50}$ s of 7.8 and $8.1 \mu \mathrm{M}$, respectively. The compounds exhibited absorbance in range 0.76-1.3. Highest absorbance of 1.079 was demonstrated by 5 . Conclusion: This study can be concluded that these derivatives may have enough potential to be used as antioxidants and open new doors for research perspectives towards the development of novel radical scavenging moiety.
\end{abstract}

Key words: Murrayanine, Carbazole, Schiff's base, Anti-oxidant, Semi-synthetic.

\section{INTRODUCTION}

Free radicals like superoxide anion radical $\left(\mathrm{O}_{2}^{-}\right)$, hydroxyl radical (HO), alkyl radical $(\mathrm{R} \cdot)$, alkoxy radical (RO'), peroxy radical (ROO) and nitric oxide radical (NO) are generated through catalysis of enzymes or transition metals in chemical or biological systems, leading to cancer, lipid peroxidation, cellular damage and aging. ${ }^{1}$ In human body thousands of free radicals are generated everyday, which often leads to oncogenic proliferation, damage deoxyribosyl backbone of DNA, accelerate oxidation of polydesat- urated fatty acids, amino acids, and several other co-factors. ${ }^{2,3}$ Several natural products like flavonoids and their analogues, natural heterocyclic moieties, and miscellaneous molecules of natural origin have been reported to exhibit multifarious biological activities, of them, anti-oxidant activity remained a principle subject. ${ }^{4}$

Murraya koenigii L. or Curry tree (Rutaceae) is an important traditional herb of Indian origin that has been in practice for centuries. ${ }^{5}$ It is well known for its ethno pharmacological
Submission Date : 22-05-2016

Revision Date : :31-08-2016 Accepted Date : :16-09-2016

DOI: 10.5530/ijper.50.4.12 Correspondence:

Ruchi S. Shivhare, PhD Assistant Professor, Department of Pharmaceutical Chemistry, Kamla Nehru College of Pharmacy, Nagpur 441108, Maharashtra, INDIA.

E-mail: shivharer4@gmail. com

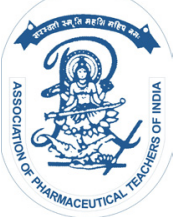

www.ijper.org 


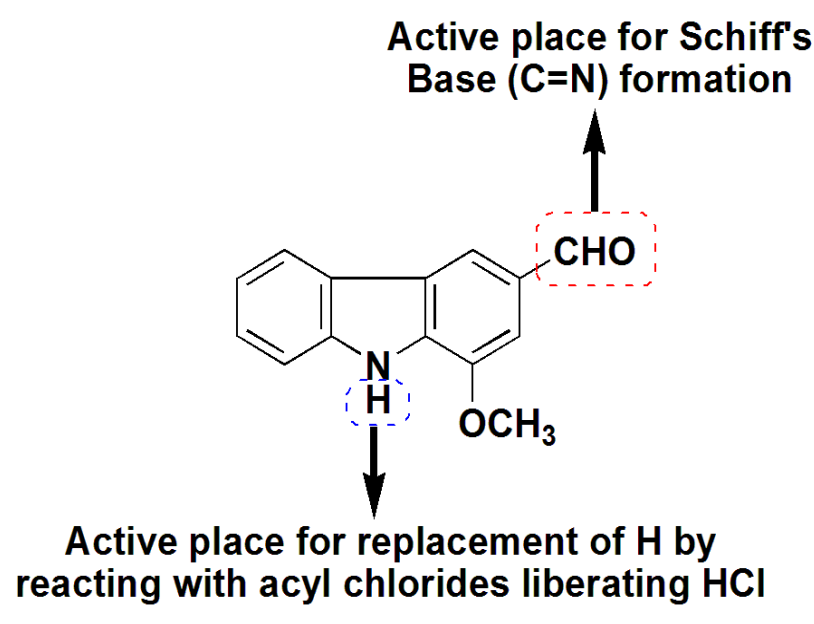

Figure 1: Rational behind synthesis of derivatives: places for substitution.

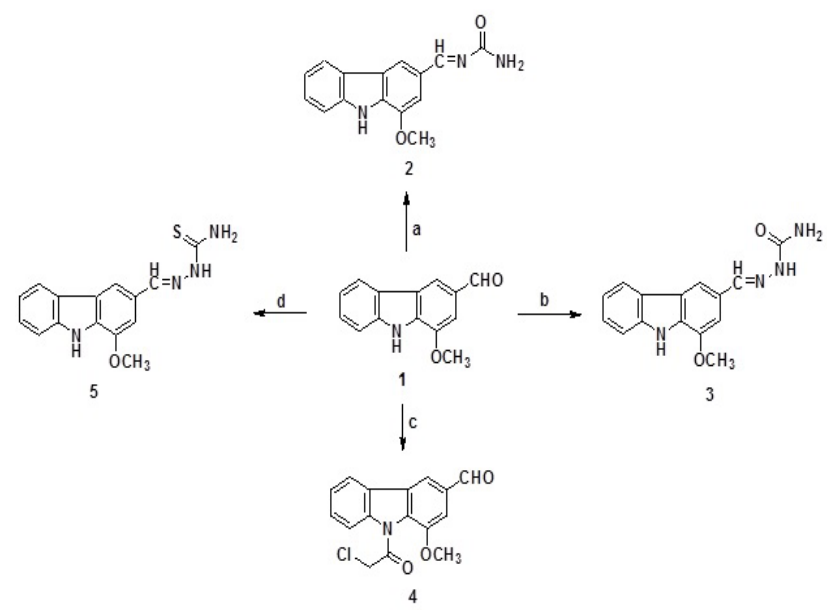

Scheme 1: Synthetic scheme of Schiff's base derivatives of murryanine. (a) urea, dil. $\mathrm{HCl}, 6 \mathrm{hr}, 70-75 \mathrm{rpm}$ (b) semicarbazide, $12 \mathrm{hr}$, 50-60 rpm (c) chloroacetic acid, (d) thiosemicarbazide, $6 \mathrm{hr}$, aqueous ethanol media.

importance for treating various ailments including free radical induced cancer. ${ }^{6}$ Water, alcohol, hydroalcoholic and chloroform extract of $M$. koenigii $\mathrm{L}$. have demonstrated potent anti-oxidant activity owing to the presence of carbazole components. ${ }^{7}$ The phytochemical studies have revealed the presence of several alkaloids possessing carbazole moiety like murrayanine, mahanimbine, urryanine, kurryam, etc. which exhibit good anti-oxidant activity. ${ }^{8}$ Based on their order of potency in exhibiting anti-oxidant activity, well known carbazoles of $M$. koenigii have demonstrated activity based on their structural aspects in following order: mahanine $>$ bismahanine $>$ isomahanine $>$ euchrestine $\mathrm{B}>$ bispyrayafoline $>$ bismurrayafoline $>$ koenimbine $>$ O-methylmahanine $>$ O-methylmurrayamine A $>$ mahaninebicine $>$ mahaninebine. ${ }^{9}$ Numerous hybridized carbazole moieties have

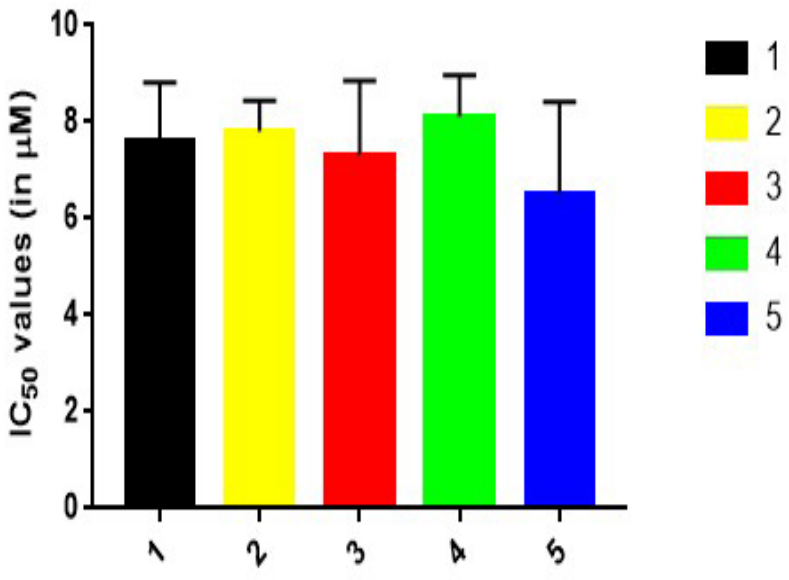

Figure 2: Anti-oxidant activity (IC50 values) of the synthesized compounds.

\begin{tabular}{|c|c|c|}
\hline Treatment & $\mathrm{IC}_{50}$ values \# & Absorbance ${ }^{\#}(700 \mathrm{~nm})$ \\
\hline 1 & $7.6 \pm 1.21$ & $0.854 \pm 0.023$ \\
\hline 2 & $7.8 \pm 0.64$ & $0.871 \pm 0.014$ \\
\hline 3 & $7.3 \pm 1.55$ & $0.988 \pm 0.046$ \\
\hline 4 & $8.1 \pm 0.87$ & $0.762 \pm 0.022$ \\
\hline 5 & $6.5 \pm 1.92$ & $1.079 \pm 0.013$ \\
\hline Ascorbic acid & $4.4 \pm 0.39$ & $1.306 \pm 0.006$ \\
\hline
\end{tabular}

Anti-oxidant activity was carried out as per DPPH assay method. \# All values represent mean \pm SEM of $n=3 ; * * * p<0.001$ with respect to standard group. Ascorbic acid was used as standard reference for anti-oxidant activity.

been reported that possess high anti-oxidant activity as compared to some substituted carbazoles. ${ }^{10}$

As the science is progressing, the harmful role of free radicals in rapidly has been highlighted and known. Recently, several anti-oxidant therapies have emerged after emergence of approved anti-oxidant molecules which might have perspectives for preventive measures in the human body. Based on the evidence that carbazole molecules have anti-oxidant effect, although quite lower than desirable, an attempt was made where the present study focuses exclusively on the rational development of few anti-oxidant molecules by hybridization or conjugation with an active moiety (like Schiff's base moiety), which often represents an impressive approach 
for increasing the biological activity of molecules by several times.

Schiff's base containing compounds have also been reported to demonstrate fair to good anti-oxidant properties. ${ }^{11-14}$ Several Schiff's bases containing natural product have displayed excellent radical scavenging properties. ${ }^{15}$ Schiff's base are aldehyde- or ketone-like compounds in which the carbonyl group is replaced by an imine or azomethine group, formed when any primary amine reacts with an aldehyde or a ketone under specific conditions. ${ }^{16}$ The present research represents an effort to develop few novel hybridized derivatives of murrayanine (an active carbazole derivative) by reacting with various small ligands like urea, chloroacetyl chloride, semi-carbazide and thio-semi carbazide with an intention to develop Schiff's base compounds with higher and potent anti-oxidant activity than its parent moiety (murrayanine).

\section{MATERIALS AND METHODS Chemistry}

The tested chemicals were analyzed at Sapience Bioanalytical Research Laboratory, Bhopal, India. Melting points were measured on Perfit melting point apparatus and are uncorrected. The infrared spectra were recorded in $\mathrm{KBr}$ discs on IRAffinity-1 instrument. The ${ }^{1} \mathrm{H}$ NMR (400 MHz). Mass spectra were obtained on JEOL-JMS-DX 303 instrument. Elemental analyses $(\mathrm{C}, \mathrm{H}, \mathrm{N})$ were performed on Perkin-Elmer 240C analyzer. All compounds were within $\pm 0.4 \%$ of the theoretical values. Thin layer chromatography was performed on silica gel G-coated TLC plates (Merck). All chemicals used for synthesis were purchased from Sigma-Aldrich and Merck.

\section{Collection and authentication}

The plant specimen for the proposed study was collected from medicinal garden of Alard College of Pharmacy, Pune, India. The plant was authenticated by A. Benniamin, PhD, Department of Botany, Pune and specimen herbarium was preserved at Botanical Survey of India (NK 01).

\section{Extraction of murryanine}

The powdered stem bark of $M$. koenigii was extracted successively with $\mathrm{n}$-hexane using soxhlet apparatus. The extract was filtered through a cotton plug, followed by Whatman filter paper. Concentrated n-hexane extract was further subjected to isolation by column chromatography over silica gel and eluted with mixture of hexane, hexane/ethyl acetate, ethyl acetate, ethyl acetate/ methanol and methanol to give about 75 fractions each. Each fraction was analyzed by TLC. Fraction $\mathrm{B}_{21}-\mathrm{B}_{37}$ crude hexane extract of stem bark were combined to give extract the parent compound murrayanine 1 . Powdered drug material was analyzed for physicochemical test and fluorescent analysis.

\section{Design and synthesis outline}

The chemical structures of the synthesized anti-oxidant molecules comprise of a carbazole scaffold. The synthesized molecules were derived from murrayanine (an active carbazole derivative) which has a well known anti-oxidant activity. As per literature, it is reported that several moieties like alkaloid, flavonoid, etc. are present in $M$. koenigii L. which exhibit anti-oxidant activities. The objective was to design molecules having better antioxidant activity than the parent murrayanine.

For the synthesis of derivatives 2-5, two active parts of murrayanine 1 were focused. The - $\mathrm{CHO}$ (aldehyde) and - NH moiety of this carbazole were suitably considered where substitution was possible (Figure 1). Schiff's bases, one of the most important components in medicinal chemistry, were taken into account for synthesis of $\mathbf{2 , 3}$ and $\mathbf{5}$, where the electrophilic carbon atom of aldehyde part of $\mathbf{1}$ (murrayanine) presume to be attacked by the nucleophilic amine moiety, which results in the replacement of $\mathrm{C}=\mathrm{O}$ by a $\mathrm{C}=\mathrm{N}$. For the synthesis of derivative 4, chloroacetyl chloride was employed for reaction, which involved a nucleophilic attack on positively charged carbon atom by the lone pair on the nitrogen atom in the carbazole scaffold. The chloride ion was removed along with the hydrogen ion from the nitrogen, producing $\mathrm{HCl}$.

To synthesize the designed compounds, a single step synthetic protocol was initiated with murrayanine 1, which was obtained by hot soxhelation of powdered stem bark of $M$. koenigii $\mathrm{L}$ by hexane. The formation of (E)-1-((1-methoxy-9H-carbazol-3-yl)methylene) urea 2 involved reacting equimolar quantity of an alcoholic solution of 1 with urea in presence of dil. HCl. For the synthesis of (E)-1-( (1-methoxy-9H-carbazol-3-yl) methylene) semicarbazide 3 , equimolar amounts of 1 and semicarbazide hydrochloride were refluxed for 12 $\mathrm{hr}$ and product was obtained suitably. The reaction by drop wise addition of chloroacetyl chloride to 1 under highly stirring in acetone medium affords scaffold 9-(2-chloroacetyl)-1-methoxy-9H-carbazole-3-carbaldehyde 4. Scaffold 5, (E)-1-((1-methoxy-9H-carbazol-3-yl) methylene) thiosemicarbazide was synthesized similar to the process mentioned for $\mathbf{3}$, where equimolar amounts of 1 and thiosemicarbazide were made to react and crys- 
tallized suitably. Scheme 1 represents the protocol for the synthesis of molecules.

\section{Synthesis of semi-synthetic derivatives 1-methoxy-9H-carbazole-3-carbaldehyde (1)}

White crystal, mp: $165-167^{\circ} \mathrm{C}, \mathrm{R}_{\mathrm{f}}: 0.47$, hexane: ethyl acetate: methanol (7:2:1). FTIR $(\mathrm{KBr}) \cup\left(\mathrm{cm}^{-1}\right): 3250$ (NH), 3081 (C-H, aromatic), 1722 (C=O), 1295 (C-O). ${ }^{1} \mathrm{H}$ NMR ( $\delta$, ppm, DMSO-d6): 4.052 (2, 1H), 7.488 (3, 1H), $10.071(4,1 \mathrm{H}), 8.226(5,1 \mathrm{H}), 8.144(6,1 \mathrm{H}, \mathrm{d}), 7.292$ $(7,1 \mathrm{H}), 7.547(8,1 \mathrm{H}, \mathrm{t}), 7.512(9,1 \mathrm{H}), 8.623(10,1 \mathrm{H})$. MS: $\left[\mathrm{M}^{+} 225 ; 181(30 \%)\right]$. Anal. Calcd for $\mathrm{C}_{11} \mathrm{H}_{12} \mathrm{ClNO}_{3}$ : C, 65.45; H, 3.66; N, 12.77. Found: C, 65.35; H, 3.50; $\mathrm{N}, 12.34$.

\section{(E)-1-( (1-methoxy-9H-carbazol-3-yl) methylene) urea (2)}

The Schiff base derivative 2 was synthesized by mixing an ethanol-methanol (50:50) solution of 1 (2.25 g; $0.01 \mathrm{M})$ with equimolar quantity of urea $(0.60 \mathrm{~g} ; 0.01 \mathrm{M})$ in presence of few drops of dil. $\mathrm{HCl}(\mathrm{pH} 4.5)$. The resultant mixture was refluxed for $6 \mathrm{hr}$ under stirring at 70-75 $\mathrm{rpm}$. The content was cooled, product in form of precipitate was separated suitably by filtration under vacuum assisted Buchnner funnel system and finally the product was recrystallized using alcoholic solution and dried at ambient temperature with $70 \%$ yield.

Buff colored solid, $43 \%$ yield; mp: $177-178^{\circ} \mathrm{C}, \mathrm{R}_{\mathrm{f}}: 0.69$, hexane: ethyl acetate: methanol (7:2:1). FTIR $(\mathrm{KBr}) \mathrm{u}$ $\left(\mathrm{cm}^{-1}\right): 3438\left(\mathrm{NH}_{2}\right), 3212(\mathrm{NH}), 3068(\mathrm{C}-\mathrm{H}$, aromatic), $1663(\mathrm{C}=\mathrm{N}$, azomethine), $1606(\mathrm{C}=\mathrm{C}$, aromatic), 1281 (C-O). ${ }^{1} \mathrm{H}$ NMR ( $\delta$, ppm, DMSO-do): $3.881(2,2 \mathrm{H})$, $8.244(4,1 \mathrm{H}), 8.332(6,1 \mathrm{H}, \mathrm{d}), 8.116(9,1 \mathrm{H}), 8.623(10$, $1 \mathrm{H}), 7.968(13,1 \mathrm{H}) 3.657(16,1 \mathrm{H}, 3 \mathrm{H})$. MS: [ $\left.\mathrm{M}^{+} 267\right]$. Anal. Calcd for $\mathrm{C}_{15} \mathrm{H}_{13} \mathrm{~N}_{3} \mathrm{O}_{2}$ : C, 67.40; H, 4.90; N, 15.72 . Found: C, 67.37; H, 4.86; N, 15.71.

\section{(E)-1-((1-methoxy-9H-carbazol-3-yl)methylene) semicarbazide (3)}

A mixture of equimolar amounts of 1 (2.25 g; 0.01 $\mathrm{M})$ and semicarbazide hydrochloride $(0.75 \mathrm{~g} ; 0.01 \mathrm{M})$ were dissolved in $50 \mathrm{ml}$ ethanol-methanol mixture and refluxed under stirring $(50-60 \mathrm{rpm})$ for $12 \mathrm{hr}$. The reaction mixture was then cooled by keeping in ice-bath to precipitate solid product. The content was filtered, recrystallized from ethanol (98\%) to produce needle like crystalline products.

White needle crystals, $63 \%$ yield; mp: $198-199^{\circ} \mathrm{C}, \mathrm{R}_{\mathrm{f}}$. 0.56, hexane: ethyl acetate: methanol (7:2:1). FTIR (KBr) v $\left(\mathrm{cm}^{-1}\right): 3423\left(\mathrm{NH}_{2}\right), 3244(\mathrm{NH}), 3064(\mathrm{C}-\mathrm{H}$, aromatic), 1661 (C=N, azomethine), 1619 ( $\mathrm{C}=\mathrm{C}$, aromatic), 1286

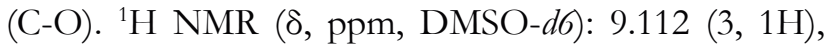

$6.978(8,1 \mathrm{H}, \mathrm{d}), 7.463$ (9, 1H, dd), $3.687(15,1 \mathrm{H}, 3 \mathrm{H})$, 7.891 (18, 1H, dddd), 7.987 (19, 1H, ddd), 7.469 (20, 1H, ddd). MS: $\left(\mathrm{M}^{+}\right.$282). Anal. Calcd for $\mathrm{C}_{15} \mathrm{H}_{14} \mathrm{~N}_{4} \mathrm{O}_{2}$ : C, 63.82; H, 5.00; N, 19.85. Found: C, 63.71; H, 4.88; N, 19.69 .

\section{9-(2-chloroacetyl)-1-methoxy-9H-carbazole-3- carbaldehyde (4)}

Chloroacetyl chloride $(0.79 \mathrm{ml}, 0.01 \mathrm{M})$ was added dropwise to a highly stirred (>100 rpm) solution of $\mathbf{1}$ ( $2.25 \mathrm{~g}$; $0.01 \mathrm{M})$ in acetone medium $(50 \mathrm{ml})$. The reaction mixture was allowed to reflux for $4 \mathrm{hr}$, separated, washed and the product was crystallized from ethyl alcohol yielding yellow crystals.

Yellow crystals, $71 \%$ yield; mp: $215-217^{\circ} \mathrm{C}, \mathrm{R}_{\mathrm{f}}: 0.77$, hexane: ethyl acetate: methanol (7:2:1). FTIR $(\mathrm{KBr}) \mathrm{u}$ $\left(\mathrm{cm}^{-1}\right)$ : $3249(\mathrm{NH}), 3077(\mathrm{C}-\mathrm{H}$, aromatic), $1738(\mathrm{C}=\mathrm{O}$, aldehyde), 1712 ( $\mathrm{C}=\mathrm{O}$, ketone), 1607 ( $\mathrm{C}=\mathrm{C}$, aromatic), 1295 (C-O), 610 (C-Cl). ${ }^{1} \mathrm{H}$ NMR ( 8 , ppm, DMSO-do): $4.685(2,2 \mathrm{H}), 8.066(11,1 \mathrm{H}, \mathrm{ddd}), 7.463(13,1 \mathrm{H}, \mathrm{d})$, 8.285 (14,1H, dd), 8.367 (15,1H, dddd), 7.584 (16,1H, ddd), $3.882(17,3 \mathrm{H}), 7.492(19,1 \mathrm{H}), 10.065$ (20,1H). MS: [M 301; $\mathrm{M}+2303(22 \%)]$. Anal. Calcd for $\mathrm{C}_{16} \mathrm{H}_{12} \mathrm{ClNO}_{3}: \mathrm{C}$, 63.69; H, 4.01; N, 4.64. Found: C, 63.58; H, 3.99; N, 4.59 .

\section{(E)-1-((1-methoxy-9H-carbazol-3-yl)methylene) thiosemicarbazide (5)}

Thiosemicarbazide $(0.91 \mathrm{~g} ; 0.01 \mathrm{M})$ in aqueous ethanol solution $(60 \mathrm{ml})$ was added slowly at $80-90^{\circ} \mathrm{C}$ with continuous stirring to an ethanolic solution of $\mathbf{1}$ (2.25 g; $0.01 \mathrm{M})$. The content was refluxed for $6 \mathrm{hr}$, cooled, the precipitate filtered off, washed with ice-cold water, dried suitably and recrystallized using aqueous ethanol as solvent.

Pale yellow crystals, $67 \%$ yield; $m p: 221-223^{\circ} \mathrm{C}, \mathrm{R}_{\mathrm{f}} 0.48$, hexane: ethyl acetate: methanol (7:2:1). FTIR (KBr) u $\left(\mathrm{cm}^{-1}\right)$ : $3411\left(\mathrm{NH}_{2}\right), 3250(\mathrm{NH}), 3076(\mathrm{C}-\mathrm{H}$, aromatic), $1664(\mathrm{C}=\mathrm{N}$, azomethine), $1613(\mathrm{C}=\mathrm{C}$, aromatic), 1285 (C-O), 1162 (C=S). ${ }^{1} \mathrm{H}$ NMR (400 MHz, $\left.\mathrm{CDCl}_{3}\right) \delta$ $9.043(3,1 \mathrm{H}), 7.463(6,1 \mathrm{H}), 6.978(8,1 \mathrm{H}, \mathrm{d}), 7.463$ (9, 1H, dd), $3.687(15,1 \mathrm{H}, 3 \mathrm{H}), 7.891(18,1 \mathrm{H}), 7.987$ (19, 1H, ddd), 7.469 (20,1H). MS: [M+298]. Anal. Calcd for $\mathrm{C}_{15} \mathrm{H}_{14} \mathrm{~N}_{4} \mathrm{OS}$ : C, 60.38; H, 4.73; N, 18.78. Found: C, 60.24; H, 4.70; N, 18.55.

\section{Biological Evaluation \\ In vitro anti-oxidant activity}

The potential of extract components to destroy the DPPH radical (1,1-diphenyl-2-picrylhydrazyl) was investigated according to Conforti $\mathrm{et} \mathrm{al.}{ }^{17}$ Stock solution of whole plant extract was prepared to the concentra- 
tion of $1 \mathrm{mg} / \mathrm{mL} .100 \mu \mathrm{g}$ concentration of extract was added at an equal volume to methanolic solution of DPPH $(0.0001 \mathrm{M})$. The aliquot was incubated for $30 \mathrm{~min}$ at room temperature. The absorbance was recorded at $517 \mathrm{~nm}$ keeping ascorbic acid as standard control.

\section{In vitro reducing activity}

The reducing power of the individual plant extracts as well as their mixture was determined according to the procedure described by Doughari et al. ${ }^{18}$ The experiment was carried out in triplicate. $100 \mu \mathrm{g} / \mathrm{ml}$ of extract was mixed into the mixture of $2.5 \mathrm{ml}$ of $0.2 \mathrm{M}$ phosphate buffer ( $\mathrm{pH} 7.4$ ) and $2.5 \mathrm{ml}$ of $1 \%$ potassium ferricynide. The mixture was then incubated at $50^{\circ} \mathrm{C}$ for 20 minutes. After incubation, $2.5 \mathrm{ml}$ of trichloroacetic acid was added to the mixture, which was then centrifuged at $3000 \mathrm{rpm}$ for $10 \mathrm{~min}$. The upper layer of the solution $(2.5 \mathrm{ml})$ was mixed with distilled water $(2.5 \mathrm{ml})$ and ferric chloride $(0.5 \mathrm{ml}, 0.1 \%)$ and the absorbance was measured at $700 \mathrm{~nm}$. The increased absorbance of the reaction mixture indicated increased reducing power.

\section{RESULTS AND DISCUSSION}

\section{Analysis and interpretation}

The novel compounds obtained in fairly high yield were measured for their physiochemical characteristics, chromatographic behavior, and elemental composition revealed their desired purity.

The analytical data further supports the formation of new molecules. The FTIR spectra of the compounds confirmed the synthesis of semi-synthetic derivatives. The presence of azomethine group $(\mathrm{HC}=\mathrm{N})$ was found to be in range of $1690-1640 \mathrm{~cm}^{-1}$ where compounds 2 , 3 and $\mathbf{5}$ displayed appearance of sharp peak at 1663 , 1661 and $1664 \mathrm{~cm}^{-1}$, respectively. The absence of band in the range of $1,700-1,750 \mathrm{~cm}^{-1}$ which represents aldehyde carbonyl further confirms the conversion of the aldehyde group to azomethine in the product. Absorption bands in the range of $3100-3250 \mathrm{~cm}^{-1}$ for $\mathrm{NH}$ and $3200-3400 \mathrm{~cm}^{-1}$ for $\mathrm{NH}_{2}$ was observed in derivatives $\mathbf{2 ,} \mathbf{3}$ and $\mathbf{5}$.

The ${ }^{1} \mathrm{H}$ NMR spectra were recorded in DMSO- $\mathrm{d}^{6} /$ $\mathrm{CDCl}_{3}$, and spectral data of compounds 2-5 have revealed that aromatic protons were present as multiplets in the range of 7.2-7.9 ppm for the free Schiff base ligands, which were slightly shifted downfield. This was assigned to a decrease in the local electron density. The azomethine proton of all the three Schiff base ligands was observed in the range of 8.01-8.19 ppm, while peaks at 8.8-9.1 ppm were observed for the NH group.
The halogen linked or substituted protons are present ranges from 3.5-4.5 ppm either as singlet or multiplet.

The mass spectra of the compounds represented the anticipated peaks. The compounds $2-5$ displayed the base peak at $\mathrm{m} / \mathrm{z} 267,282,301,298$, which closely matches with its molecular formula. In addition, the spectra also showed several fragment ion peaks including fragmented parts of the products.

\section{Anti-oxidant activity}

Free Radicals are very unstable molecules with an unpaired electron that react quickly with other compounds to capture surrounding electron to gain stability and thus initiates a chain reaction which cascades and lastly results in loss of cellular function. ${ }^{19-21}$ Averagely, 10000-20000 free radicals attack body cell each day, of them oxygen free radicals, an intermediates of dioxygen reduction resulting in damage deoxyribosyl backbone of DNA, accelerate oxidation of polydesaturated fatty acids, amino acids, co-factors. Free radicals are main culprits for precipitation of diseases like cancer Alzheimer's disease, cardiac abnormalities, nephrotic disease, neurological complications, miscellaneous metabolic syndromes, etc. ${ }^{22-23}$ Antioxidants and agents with potential to reduce free radicals scavenge these radicals and cease the chain reaction, thereby, preventing further damage. ${ }^{24}$ The DPPH radical scavenging activity and reducing power of semi-synthetic derivative reflects the prospective as antioxidants and can be employed in different pathological conditions. At present, nearly $60 \%$ of the approved anticancer drugs globally or chemo-protectant agents are derived from nature. The compounds scavenge the DPPH radical at $\mathrm{IC}_{50}$ values ranging from 6.5-8.1 $\mu \mathrm{M}$. The compound $\mathbf{5}$ exhibited highest anti-oxidant activity $\left(\mathrm{IC}_{50}\right.$ of $6.5 \mu \mathrm{M}$ ), followed by derivative 3 which displayed activity at $\mathrm{IC}_{50}$ value of $7.3 \mu \mathrm{M}$, which was superior as compared to murrayanine 1 which scavenge the radical at $\mathrm{IC}_{50}$ of $7.6 \mu \mathrm{M}$ (Figure 2). However, two semi-synthetic compounds ( 2 and 4 ) exhibited lesser activity compared to murrayanine, $\mathrm{IC}_{50} \mathrm{~s}$ of 7.8 and $8.1 \mu \mathrm{M}$, respectively. The compounds exhibited absorbance in range $0.76-1.3$. Highest absorbance of 1.079 was demonstrated by $\mathbf{5}$ followed by $\mathbf{3}, \mathbf{2}$ and $\mathbf{1}$. In contrast, compound 4 exhibited lowest absorbance of 0.762 (Table 1). However, all compounds demonstrated activity lesser than that of standard, ascorbic acid.

The mechanism(s) for free radical scavenging is not known exactly; however probable mechanism(s) involve the interaction between the hydroxyl functional group of the carbazole derivatives and the DPPH; where sequential proton loss electron transfer (SPLET) is an indication of the ability of the antioxidant to scavenge 
free radicals. ${ }^{25}$ The study highlighted that the structure has a key influence on biological activity. The structureactivity relationship may be established where it was observed that carbazole scaffold remained a foremost need for exhibiting anti-oxidant activity. From the obtained results, it may be envisaged that substitution of a nitrogen containing fragment in C-3 position may be essential for increasing the potency of derivatives. The derivatives having substituted C-3 position (2, 3 and 5) has displayed better potency than unsubstituted (4). It may also be fair to predict that (thio)semicarbazide moiety has a key role in combating the free radicals and is considered an essential component for enhancing the antioxidant effect.

These results further suggested that the compounds have good antioxidant properties along with low cytotoxicity which could exert protective effects against oxidative and free radical injuries occurring in oxidative stress-related diseases like cancer. The results further justify that the compounds have the potential to undergo a clinical trial. In the past few years, several molecules like idebenone, latrepirdine, epigallocatechine, resveratrol, curcumin underwent clinical trials for exploration of their beneficial effects in neurodegenerative diseases. ${ }^{26}$ However, the results are not sufficiently clear; whether it has improved the quality of life of individuals or any marked improvements. In this decade, the only carbazole scaffold bearing non-selective $\beta$-blocking agent carvedilol has received adequate attention due to its pronounced antioxidant effect that has a limited perspective in patients with a background of cardiac complication or stable angina owing to cardioprotective activity. ${ }^{27}$ At present, none of the carbazole-based antioxidants are in clinical trial or is as popular to be employed successfully. Therefore it can be concluded that the carbazoles and their semi-synthetic derivatives of M. koenigii origin may have enough potential to be used as antioxidants in future.

\section{CONCLUSION}

Antioxidants are getting a high importance in healthcare due to some recently proven benefits in treating several ailments. The evidences from the experimental and clinical researches have indicated that regular intake of antioxidants helps reducing the risk of cognitive deterioration. The present study was an attempt to develop better anti-oxidant derivatives than murrayanine. The compounds exhibited good anti-oxidant activity which reflected that there is a perspective of developing still better analogues that will have enhanced activity compared to parent compound. Therefore, this study opened new doors for research perspectives towards the rational development of novel radical scavenging moiety.

\section{ACKNOWLEDGEMENT}

Authors are highly thankful to Savitribai Phule Pune University, Pune, Maharashtra, India for providing research grants (Grant No. 13PHM000126).

\section{CONFLICT OF INTEREST}

Authors have no conflict of interest with the content of this article.

\section{ABBREVIATION USED}

(O2 -): Superoxide anion radical; (HO.): Hydroxyl radical; (R.): Alkyl radical; (RO.): Alkoxy radical; (ROO.): peroxy radical; (NO.): Nitric oxide radical.

\section{REFERENCES}

1. Zhang HY. Structure-activity relationships and rational design strategies for radical-scavenging antioxidants. Curr Comput Aided Drug Des. 2005;1(3):257-73. http://dx.doi.org/10.2174/1573409054367691.

2. Valko M, Rhodes CJ, Moncol J, Izakovic M, Mazur M. Free radicals, metals and antioxidants in oxidative stress-induced cancer. Chem Biol Interact. 2006;160(1):1-40. http://dx.doi.org/10.1016/j.cbi.2005.12.009; PMid:16430879.

3. Stohs SJ. The role of free radicals in toxicity and disease. J Basic Clin Physiol Pharmacol. 1995;6(3-4):205-28. http://dx.doi.org/10.1515/JBCPP.1995. 6.3-4.205; PMid:8852268.

4. Mahapatra DK, Bharti SK, Asati V. Anti-cancer chalcones: Structural and molecular target perspectives. Eur J Med Chem. 2015;98:69-114. http:// dx.doi.org/10.1016/j.ejmech.2015.05.004; PMid:26005917.

5. Nayak A, Mandal S, Banerji A, Banerji J. Review on chemistry and pharmacology of Murraya koenigii Spreng (Rutaceae). J Chem Pharm Res. 2010;2(2):286-99.

6. Handral HK, Pandith A, Shruthi SD. A review on Murraya koenigii: multipotential medicinal plant. Asian J Pharm Clin Res. 2012;5(4):5-14.

7. Ningappa MB, Dinesha R, Srinivas L. Antioxidant and free radical scavenging activities of polyphenol-enriched curry leaf (Murraya koenigii L.) extracts. Food Chem. 2008;106(2):720-8. http://dx.doi.org/10.1016/j. foodchem.2007.06.057.

8. Tachibana $\mathrm{Y}$, Kikuzaki $\mathrm{H}$, Lajis $\mathrm{NH}$, Nakatani N. Antioxidative activity of carbazoles from Murraya koenigii leaves. J Agri Food Chem. 2001;49(11):5589-94. http://dx.doi.org/10.1021/jf010621r .

9. Tachibana Y, Kikuzaki H, Lajis NH, Nakatani N. Comparison of antioxidative properties of carbazole alkaloids from Murraya koenigii leaves. J Agri Food Chem. 2003;51(22):6461-7. http://dx.doi.org/10.1021/jf034700+ PMid:14558763.

10. Głuszyńska A. Biological potential of carbazole derivatives. Eur J Med Chem. 2015;94:405-26. http://dx.doi.org/10.1016/j.ejmech.2015.02.059; PMid:25794500.

11. Valentina P, llango K, Deepthi M, Harusha P, Pavani G, Sindhura KL, et al. Antioxidant activity of some substituted 1, 2, 4-triazo-5-thione Schiff base. J Pharm Sci Res. 2009;1(2):74-7.

12. Alam MS, Choi JH, Lee DU. Synthesis of novel Schiff base analogues of 4-amino-1,5-dimethyl-2-phenylpyrazol-3-one and their evaluation for antioxidant and anti-inflammatory activity. Bioorg Med Chem. 2012;20(13):4103-8. http:// dx.doi.org/10.1016/j.bmc.2012.04.058; PMid:22626550.

13. Ceyhan G, Çelik C, Uruş S, Demirtaş I, Elmastaş M, Tümer M. Antioxidant, electrochemical, thermal, antimicrobial and alkane oxidation properties 
of tridentate Schiff base ligands and their metal complexes. Spectrochim Acta Mol Biomol Spectrosc. 2011;81(1):184-98. http://dx.doi.org/10.1016/j. saa.2011.05.106 PMid:21752697.

14. Karatepe M, Karatas F. Antioxidant, pro-oxidant effect of the thiosemicarbazone derivative Schiff base (4-(1-phenylmethylcyclobutane3-yl)-2-(2-hydroxybenzylidenehydrazino) thiazole) and its metal complexes on rats. Cell Biochem Funct. 2006;24(6):547-54. http://dx.doi.org/10.1002/ cbf.1266 ; PMid:16143962.

15. Li TR, Yang ZY, Wang BD. Synthesis, characterization and antioxidant activity of naringenin Schiff base and its $\mathrm{Cu}$ (II), Ni (II), Zn (II) complexes. Chem Pharm Bull. 2007;55(1):26-8. http://dx.doi.org/10.1248/cpb.55.26

16. Bharti SK, Nath G, Tilak R, Singh SK. Synthesis, anti-bacterial and anti-fungal activities of some novel Schiff bases containing 2, 4-disubstituted thiazole ring. Eur J Med Chem. 2010;45(2):651-60. http://dx.doi.org/10.1016/j. ejmech.2009.11.008; PMid:19932927.

17. Conforti F, Sosa S, Marrelli M, Menichini F, Statti GA, Uzunov D, et al. In vivo anti-inflammatory and in vitro antioxidant activities of Mediterranean dietary plants. J Ethnopharmacol. 2008;116(1):144-151. http://dx.doi.org/10.1016/j. jep.2007.11.015; PMid:18164564.

18. Doughari JH, Ndakidemi PA, Human IS, Benade S. Antioxidant, antimicrobial and antiverotoxic potentials of extracts of Curtisia dentata. J Ethnopharmacol. 2012;141(3):1041-50. http://dx.doi.org/10.1016/j.jep.2012.03.051; PMid:22504170.

\section{PICTORIAL ABSTRACT}

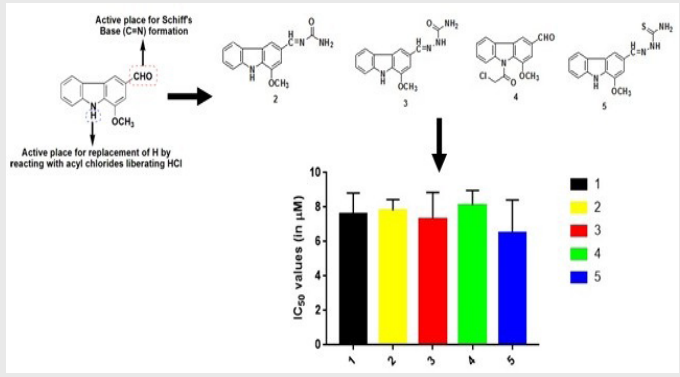

\section{About Authors}

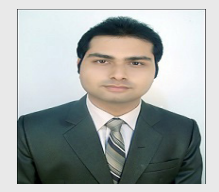

Debarshi Kar Mahapatra: Is currently teaching medicinal and computational chemistry at both undergraduate and post-graduate levels. He has mentored few students in their dissertation and carried out various national research projects. His current area of interest involves computer assisted rational designing and synthesis of low molecular weight ligands. He has authored a book entitled Drug Design and edited a book entitled Handbook of Research in Medicinal Chemistry. He has presented research at several international platforms, for which he received several awards. He is a member of a number of professional and scientific societies as well as serving the position of reviewer and editorial board member of various international journals.

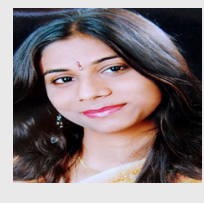

Ruchi S. Shivhare: Is presently working as Assistant Professor in Kamla Nehru College of Pharmacy. She has more than 7 years of teaching medicinal and organic chemistry at both undergraduate and post-graduate levels. Her research interest includes rational design of small molecular weight ligands as therapeutic inhibitors and chemistry of natural products. She has published few research, review, book chapter and case studies in journals of international repute. 